\title{
Hubungan Habitual Snoring dengan Prestasi Akademis Anak Sekolah Dasar
}

\author{
Hendri Tanu Jaya, Darmawan B. Setyanto, Hanifah Oswari \\ Departemen Ilmu Kesehatan Anak, Fakultas Kedokteran Indonesia/Rumah Sakit Cipto Mangunkusumo, \\ Jakarta
}

\begin{abstract}
Latar belakang. Habitual snoring dapat menimbulkan berbagai komplikasi. Berbagai penelitian menunjukkan terdapat hubungan antara habitual snoring dengan prestasi akademis anak yang rendah, tetapi belum terdapat penelitian mengenai hal ini di Indonesia.

Tujuan. Mengetahui hubungan habitual snoring dengan prestasi anak sekolah dasar berdasarkan rata-rata nilai mata pelajaran matematika, Bahasa Indonesia, dan IPA.

Metode. Desain studi potong lintang dengan kriteria inklusi berupa anak habitual snoring dan non snoring minimal 6 bulan sebelum penelitian ini berdasarkan kuesioner yang diisi oleh orangtua anak.

Hasil. Didapatkan prevalens snoring 29,3 dari 249 subjek dengan prevalens occasional snoring 20,08\% dan habitual snoring 9,24\%. Prevalens habitual snoring pada anak laki-laki lebih tinggi dibandingkan anak perempuan $(10,87 \%$ vs $7,2 \%)$ tetapi tidak bermakna secara statistik. Prevalens habitual snoring pada subjek kelompok usia $>9$ tidak berbeda bermakna dibandingkan dengan kelompok usia $\leq 9$ tahun. Dari 199 subjek yang memenuhi kriteria inklusi penelitian, terdiri dari 176 subjek non snoring dan 23 habitual snoring. Kelompok subjek habitual snoring memiliki pencapaian nilai rerata mata pelajaran matematika lebih rendah 11,47 point (nilai $\mathrm{p}=0,001$ ), mata pelajaran IPA lebih rendah 10,75 point (nilai $\mathrm{p}=0,001$ ), Bahasa Indonesia lebih rendah 8,01 point (nilai $\mathrm{p}=0,01$ ), dan pencapaian nilai rerata yang lebih rendah 10,8 point (nilai $\mathrm{p}=0,001$ ) berdasarkan rata-rata nilai dari ketiga mata pelajaran tersebut dibandingkan kelompok subjek non snoring.

Kesimpulan. Anak habitual snoring memiliki prestasi akademis yang lebih rendah dibandingkan dengan anak non snoring. Sari Pediatri 2014;15(5):313-8.
\end{abstract}

Kata kunci: habitual snoring, anak sekolah dasar, prestasi akademis

poring (mendengkur) adalah suara getaran yang terjadi saat tidur di dalam saluran napas karena adanya getaran jaringan lunak di daerah orofaring. Mendengkur merupakan tanda

Alamat korespondensi:

Dr. Hendri Tanu Jaya, Sp.A. Villa Tomang Mas Blok H No. 3,Duri Kepa Jakarta. Telp. (021) 5653063 E-mail: hendri_tanu@idai.or.id adanya sumbatan saluran napas bagian atas, dan dapat menimbulkan gangguan pernapasan sehingga terjadi hipoksia dan hiperkapnea. ${ }^{1,2}$ Mendengkur merupakan gejala utama adanya sleep-disordered breathing, tanda adanya peningkatan resistensi saluran napas bagian atas dan memiliki hubungan yang erat dengan obstructive sleep apnea syndrome (OSAS). ${ }^{3,4}$

Secara umum, mendengkur dibedakan menjadi 
habitual snoring dan occasional snoring. Habitual snoring adalah mendengkur yang terjadi $\geq 3$ kali dalam seminggu, sedangkan occasional snoring terjadi $<3$ kali dalam seminggu. ${ }^{2,4}$ Habitual snoring dapat dibagi menjadi primary snoring, upper airway resistance syndrome (UARS) dan obstructive sleep apnea syndrome (OSAS). Primary snoring adalah mendengkur tanpa adanya apnea atau hipopnea, sedangkan UARS dan OSAS adalah mendengkur yang disertai gangguan pernapasan. ${ }^{2,5}$ Pemeriksaan polysomnography merupakan baku emas untuk diagnostik mendengkur, tetapi memerlukan biaya yang mahal sehingga dalam penelitian ini tidak dibedakan antara primary snoring, UARS, maupun OSAS. ${ }^{1,2,6}$

Habitual snoring dapat menimbulkan komplikasi, berupa gangguan neurocognitive dan neurobehavioral, gangguan pertumbuhan, dan kor pulmonal. ${ }^{7-15}$ Anak habitual snoring dapat mengalami gangguan tidur sehingga mengantuk di siang hari, merasa lelah, tidak mood, dan sulit memusatkan perhatian saat menerima pelajaran sehingga mengalami penurunan prestasi dalam bidang akademis. ${ }^{5,14-17}$ Beberapa penelitian sebelumnya menunjukkan bahwa anak yang mengalami habitual snoring memiliki prestasi akademis yang lebih rendah dibandingkan yang tidak mendengkur (non snoring) dalam mata pelajaran matematika, bahasa, dan ilmu pengetahuan alam..$^{9,14,18,19}$

Prevalens mendengkur pada anak bervariasi, 9\%-31,6\% dengan prevalens habitual snoring sekitar 5,2\%-27,3\% dan OSAS 0,7\%-10,3\%., . $^{3,614,20-}$ 22 Supriyatno dkk pada tahun 2005 menyatakan prevalens mendengkur pada anak usia 5-13 tahun di Jakarta Selatan adalah 31,6\%, terdiri dari 26,4\% occasional snoring dan $5,2 \%$ habitual snoring. ${ }^{15}$ Penelitian ini dilakukan untuk mengetahui hubungan antara habitual snoring dengan prestasi akademis anak di sekolah.

\section{Metode}

Desain penelitian potong lintang dengan subjek murid SDN Jakarta Barat dilakukan pada bulan Juli 2012. Kriteria inklusi adalah anak habitual snoring dan non snoring minimal 6 bulan sebelum penelitian. Kriteria eksklusi berupa data tidak lengkap. Semua subjek dikelompokkan berdasarkan kuesioner yang diisi oleh orangtua. Prestasi akademis sebagai variable outcome (dependen) dinilai berdasarkan nilai mata pelajaran matematika, Bahasa Indonesia, ilmu pengetahuan alam, dan rata-rata nilai dari ketiga mata pelajaran tersebut diambil dari nilai raport terakhir. Pengambilan sampel dilakukan secara total sampling. Analisis bivariat menggunakan uji hipotesis T test tidak berpasangan, sedangkan analisis multivariat menggunakan analisis multivariat regresi linear.

\section{Hasil}

Terdapat 282 orang murid, 199 subjek memenuhi kriteria inklusi dan diikutsertakan dalam penelitian (176 subjek non snoring dan 23 subjek habitual snoring). Sebaran subjek menurut karakteristik demografik tertera pada Tabel 1. Subjek dikelompokkan menjadi dua kelompok berdasarkan median usia $>9$ dan $\leq 9$ tahun karena sebaran usia subjek tidak normal secara statistik.

Sebaran karakteristik kelompok subjek habitual snoring dan non snoring berdasarkan usia, jenis kelamin, dan status gizi tertera pada Tabel 2. Hubungan antara subjek yang mengalami habitualsnoring, jenis kelamin, dan obesitas dengan nilai mata pelajaran matematika, IPA, bahasa Indonesia, dan rata-rata nilai dari ketiganya tertera pada Tabel 3.

\section{Analisis multivariat}

Dari data yang ada, didapatkan bahwa habitual

Tabel.1. Sebaran karakteristik subjek penelitian

\begin{tabular}{lcc}
\hline Karakteristik & $\mathrm{n}=199$ & $(\%)$ \\
\hline Jenis kelamin & & \\
$\quad$ Lelaki & 108 & 54,3 \\
$\quad$ Perempuan & 91 & 45,7 \\
Kelompok umur (tahun) & & \\
$\quad>9$ & 80 & 40,2 \\
$\quad \leq 9$ & 119 & 59,8 \\
Status nutrisi & & \\
$\quad$ Kurang & 55 & 27,6 \\
$\quad$ Baik & 100 & 50,3 \\
$\quad$ Overweight & 22 & 11,1 \\
$\quad$ Obesitas & 22 & 11,1 \\
Riwayat penyakit asma & & \\
$\quad$ Ya & 1 & 0,5 \\
$\quad$ Tidak & 198 & 95,5 \\
Snoring & & \\
$\quad$ Non snoring & 176 & 88,4 \\
$\quad$ Habitual snoring & 23 & 11,6 \\
\hline
\end{tabular}


Hendri Tanu Jaya dkk: Hubungan habitual snoring dengan prestasi akademis anak sekolah dasar

Tabel 2. Sebaran karakteristik kelompok subjek habitual snoring dan non Snoring

\begin{tabular}{lccccc}
\hline Karakteristik & \multicolumn{2}{c}{ Non Snoring } & \multicolumn{2}{c}{ Habitual snoring } & \multirow{2}{*}{$\mathrm{p}$} \\
\cline { 2 - 4 } & $\mathrm{n}=176$ & $\%$ & $\mathrm{n}=23$ & $\%$ & \\
\cline { 1 - 4 } Kelompok umur (tahun) & 106 & 89,1 & 13 & 10,9 & \multirow{2}{*}{0,73} \\
$\quad \leq 9$ & 70 & 87,5 & 10 & 12,5 & \\
$\quad>9$ & & & & & \\
Jenis kelamin & 93 & 86,1 & 15 & 13,9 & 0,263 \\
$\quad$ Lelaki & 83 & 91,2 & 8 & 8,8 & \\
$\quad$ Perempuan & & & & & \\
Status gizi & 48 & 87,3 & 7 & 12,7 & 0,561 \\
$\quad$ Kurang* & 88 & 88,0 & 12 & 12,0 & \\
Baik* & 21 & 95,5 & 1 & 4,5 & \\
$\quad$ Overweight* & 19 & 86,4 & 3 & 13,6 & \\
$\quad$ Obesitas & & &
\end{tabular}

*) Digabung jadi satu kelompok dalam uji statistik (Fisher).

snoring secara bermakna dapat menurunkan nilai mata pelajaran Bahasa Indonesia 7,5 point, sedangkan jenis kelamin perempuan dapat menambah nilai 3 point (Tabel 4).

\section{Pembahasan}

Mendengkur terjadi karena peningkatan resistensi jalan napas, peningkatan usaha bernapas, dan aliran turbulen akibat usaha udara melalui saluran napas yang menyempit karena adanya sumbatan atau hambatan aliran udara pada saat inspirasi sehingga timbul suara mendengkur. ${ }^{10}$ Faktor risiko terjadinya mendengkur, antara lain usia, disproporsi kraniofasial, hipertrofi tonsil, dan atau adenoid, makroglosia, infeksi saluran pernapasan atas, obesitas, atopi, dan asma. ${ }^{2,6,14-}$ 16,19,20,23-29 Mendengkur lebih sering terjadi pada orang dewasa. ${ }^{14,15}$ Pada anak usia 3-8 tahun sering terjadi karena adanya pembesaran kelenjar tonsil dan adenoid. ${ }^{2,6}$ Beberapa pemeriksaan yang dilakukan untuk mendiagnosis mendengkur, seperti polisomnografi, uji tapis (kuesioner, rekaman video, pulse oxymetri untuk monitoring desaturasi saat tidur), dan hematologi rutin untuk melihat adanya polisetemia akibat hipoksia kronik. $^{2,5,9,20,24,26,27}$

Prevalens snoring penelitian kami 29,3\%. Data tersebut mendekati hasil penelitian yang dilaporkan oleh Supriyatno $\mathrm{dkk}^{19}(31,6 \%)$ pada tahun 2005. Dari penelitian ini, didapatkan prevalens occasional snoring 20,08\%, sedangkan habitual snoring 9,24\%. Prevalens habitual snoring ini sesuai dengan kepustakaan (5,2\%-27,3\%). ${ }^{1,3,12}$ Prevalens habitual snoring pada anak laki-laki lebih tinggi dibandingkan perempuan $(10,87 \%$ vs $7,2 \%)$, tetapi tidak bermakna, sama seperti yang dilaporkan oleh $\mathrm{Li} \mathrm{dkk}^{4}$ dan Li $\mathrm{dkk}^{23}$ pada tahun 2010. Berbeda dengan beberapa kepustakaan yang mengatakan bahwa anak usia 3-8 tahun lebih sering mendengkur karena adanya pembesaran kelenjar tonsil dan adenoid, tidak didapatkan adanya perbedaan pada subjek kelompok usia $>9$ tahun (10,75\%) dibandingkan dengan kelompok usia $\leq 9$ tahun $(8,33 \%) .{ }^{2,6} \mathrm{Hal}$ tersebut mungkin disebabkan adanya riwayat atopi dan pajanan asap rokok yang lebih tinggi pada anak kelompok usia $>9$ tahun.

Occasional snoring umumnya benign, sedangkan habitual snoring dapat menimbulkan berbagai komplikasi berdasarkan ada atau tidaknya hipoksia yang dialami anak pada saat tidur. Beberapa komplikasi yang dapat ditemukan pada anak habitualsnoring, antara lain gangguan tidur, gangguan neurocognitive dan neurobehavioral, gangguan pertumbuhan, enuresis, kelainan kardiovaskular, kelainan respiratorik, dan desaturasi perioperatif, bahkan kematian saat perioperatif., $5,14-19,21,22,26,30,31$ Berbeda dengan OSAS, primary snoring umumnya hanya menyebabkan gangguan tidur, gangguan neurocognitive dan neurobehavioral. Dikatakan 59\% anak habitual snoring memiliki nilai yang lebih rendah pada mata pelajaran matematikan, bahasa, dan ilmu pengetahuan alam dengan atau tanpa adanya hipoksia pada saat tidur. ${ }^{15,18}$

Dari analisis prestasi akademis sebagai variable outcome (dependen), didapatkan bahwa kelompok subjek habitual snoring memiliki pencapaian nilai rerata lebih 
Tabel 3. Hubungan antara habitual snoring, jenis kelamin, dan obesitas dengan nilai mata pelajaran matematika, IPA, Bahasa Indonesia $(\mathrm{n}=199)$

\begin{tabular}{|c|c|c|c|c|}
\hline Variabel & $\mathrm{n}(\%)$ & Rerata $\pm S B$ & $\mathrm{x} 1-\mathrm{x} 2$ & $\mathrm{p}$ \\
\hline \multicolumn{5}{|l|}{$\begin{array}{l}\text { Pelajaran Matematika } \\
\text { Snoring }\end{array}$} \\
\hline Non snoring & $176(88,44)$ & $75,56 \pm 9,06$ & 11,47 & 0,001 \\
\hline $\begin{array}{l}\text { Habitual snoring } \\
\text { Jenis kelamin }\end{array}$ & $23(11,56)$ & $64,09 \pm 10,55$ & & \\
\hline $\begin{array}{l}\text { Lelaki } \\
\text { Perempuan }\end{array}$ & $\begin{array}{l}108(54,3) \\
91 \quad(45,7)\end{array}$ & $\begin{array}{l}74,18 \pm 10,36 \\
74,3 \pm 9,44\end{array}$ & 0,12 & 0,93 \\
\hline \multicolumn{5}{|l|}{ Obesitas } \\
\hline $\begin{array}{l}\text { Ya } \\
\text { Tidak }\end{array}$ & $\begin{array}{l}22(11,06) \\
177(88,94)\end{array}$ & $\begin{array}{c}74,41 \pm 12,07 \\
74,21 \pm 9,66\end{array}$ & 0,2 & 0,941 \\
\hline \multicolumn{5}{|l|}{$\begin{array}{l}\text { Pelajaran IPA } \\
\text { Snoring }\end{array}$} \\
\hline Non snoring & $176(88,44)$ & $77,92 \pm 8,23$ & 10,75 & 0,001 \\
\hline $\begin{array}{l}\text { Habitual snoring } \\
\text { Jenis kelamin }\end{array}$ & $23(11,56)$ & $67,17 \pm 11,32$ & & \\
\hline Lelaki & $108(54,3)$ & $76,31 \pm 9,24$ & 0,81 & 0,358 \\
\hline Perempuan & $91 \quad(45,7)$ & $77,12 \pm 9,35$ & & \\
\hline Obesitas & & & & \\
\hline Ya & $22(11,06)$ & $77,95 \pm 10,3$ & 1,43 & 0,538 \\
\hline Tidak & $177(88,94)$ & $76,52 \pm 9,16$ & & \\
\hline \multicolumn{5}{|c|}{$\begin{array}{l}\text { Pelajaran Bahasa Indonesia } \\
\text { Snoring }\end{array}$} \\
\hline Non snoring & $176(88,44)$ & $77,36 \pm 7,99$ & 8,01 & 0,01 \\
\hline $\begin{array}{l}\text { Habitual snoring } \\
\text { Jenis kelamin }\end{array}$ & $23(11,56)$ & $69,35 \pm 10,19$ & & \\
\hline Lelaki & $108(54,3)$ & $75,03 \pm 8,77$ & 3,08 & 0,11 \\
\hline Perempuan & $91 \quad(45,7)$ & $78,11 \pm 8,21$ & & \\
\hline \multicolumn{5}{|l|}{ Obesitas } \\
\hline Ya & $22(11,06)$ & $76,77 \pm 9,77$ & 0,37 & 0,864 \\
\hline Tidak & $177(88,94)$ & $76,40 \pm 8,51$ & & \\
\hline \multicolumn{5}{|c|}{$\begin{array}{l}\text { Rerata mata pelajaran matematika, IPA, } \\
\text { dan B. Indonesia } \\
\text { Snoring }\end{array}$} \\
\hline Non snoring & $176(88,44)$ & $76,95 \pm 7,57$ & 10,08 & 0,001 \\
\hline Habitual snoring & $23(11,56)$ & $66,87 \pm 10,02$ & & \\
\hline \multicolumn{5}{|l|}{ Jenis kelamin } \\
\hline Lelaki & $108(54,3)$ & $75,12 \pm 8,66$ & 1,39 & 0,267 \\
\hline Perempuan & $91 \quad(45,7)$ & $76,51-8,30$ & & \\
\hline \multicolumn{5}{|l|}{ Obesitas } \\
\hline Ya & $22(11,06)$ & $76,38 \pm 9,89$ & 0,67 & 0,763 \\
\hline Tidak & $177(88,94)$ & $75,71 \pm 8,34$ & & \\
\hline
\end{tabular}

Tabel 4. Analisis multivariat hubungan antara habitual snoring dan jenis kelamin perempuan dengan nilai Bahasa Indonesia

\begin{tabular}{|c|c|c|c|c|}
\hline \multirow{2}{*}{$\begin{array}{l}\text { Variabel dependen : } \\
\text { nilai Bahasa Indonesia }\end{array}$} & \multirow{2}{*}{ B } & \multirow{2}{*}{ Sig } & \multicolumn{2}{|c|}{$95 \%$ CI for B } \\
\hline & & & Lower & Upper \\
\hline (Constant) & 77,297 & 0,000 & 75,524 & 79,070 \\
\hline Habitual snoring & $-7,491$ & 0,000 & $-11,005$ & $-3,977$ \\
\hline Perempuan & 3,166 & 0,007 & 0,892 & 5,441 \\
\hline
\end{tabular}


rendah dibandingkan kelompok subjek non snoring pada mata pelajaran matematika, IPA, dan Bahasa Indonesia, serta rata-rata nilai ketiga mata pelajaran tersebut. Serupa dengan penelitian lain sebelumnya, tetapi Bahasa Indonesia adalah yang pertama kali digunakan., $14,18,19$ Mekanisme penurunan prestasi akademis pada anak habitualsnoring sampai saat ini belum diketahui dengan jelas, mungkin disebabkan oleh adanya gangguan tidur ${ }^{5,14-17}$ Gangguan tidur dan hipoksia juga merupakan penyebab timbulnya gangguan neurocognitive dan neurobehavioral ${ }^{-15}$ Kurun waktu yang diperlukan sampai timbulnya komplikasi belum diketahui dengan pasti, tetapi minimal dalam kurun waktu $6 \mathrm{~b}$ ulan berdasarkan studi ini telah diketahui dapat memiliki prestasi yang lebih rendah sehingga diperlukan pemantauan yang serius dan intervensi segera sesuai penyebab atau faktor risiko penyebab mendengkur. Tata laksana habitual snoring dapat bersifat operatif dan non operatif. Tindakan operatif diperlukan jika terdapat kelainan anatomis atau pembesaran kelenjar tonsil dan adenoid, sedangkan terapi medikamentosa, penurunan berat badan pada anak obesitas, atau pengunaan continuous positive airway pressure pada anak yang OSAS merupakan tindakan yang bersifat non operatif. Anak mendengkur disarankan untuk tidur dengan posisi miring, untuk mengurangi/mencegah mendengkur pada saat tidur dengan dasar pemikiran, bahwa dapat mencegah pangkal lidah jatuh kedalam dasar rongga mulut, sehingga dapat mencegah timbulnya obtruksi jalan napas yang dapat mengakibatkan mendengkur.

Keterbatasan penelitian kami adalah penggunaan desain uji hipotesis potong lintang. Hal tersebut memungkinkan pendapat orangtua menjadi kurang tepat karena waktu yang kurang dalam memantau kebiasaan anak selama tidur. Selain itu, habitualsnoring hanya berdasarkan jawaban yang diberikan orangtua melalui kuesioner sehingga jawaban yang diberikan dapat bersifat subjektivitas orangtua. Kelebihan penelitian ini, yaitu pertama kali di Indonesia meneliti hubungan habitualsnoring dengan nilai akademis anak sekolah dasar.

\section{Kesimpulan}

Anak yang mengalami habitual snoring memiliki prestasi akademis yang lebih rendah dibandingkan dengan anak yang non snoring dalam bidang matematika, bahasa Indonesia dan IPA.

\section{Daftar pustaka}

1. American Thoracic Society . Standards and indications for cardiopulmonary sleep studies in children. Am J Respir Crit Care Med 1995;153:866-78.

2. Supriyatno B. Obstructive sleep apnea syndrome (OSAS) pada anak. Dalam: Rahajoe NN, Supriyatna B, Setyanto $\mathrm{DB}$, penyunting. Buku ajar respirologi anak. Edisi pertama. Jakarta: IDAI; 2008.h.402-11.

3. Montgomery-Downs HE, O’Brien LM, Holbrook CR, Gozal D. Snoring and sleep-disordered breathing in young children: subjective and objective correlates. Sleep 2004;27:87-94.

4. Li S, Jin X, Yan C, Wu S, Jiang F, Shen X. Habitual snoring in school-aged children: environmental and biological predictors. Respir Res 2010;1:144-53.

5. Owens JA. Sleep medicine. Dalam: Kliegman RM, Behrman RE, Jenson HB, Stanton BF, penyunting. Nelson texbook of pediatrics. Edisi ke-18. Philadelphia: Saunders Elsevier; 2007.h.94-7.

6. American Academy of Pediatrics, Section on Pediatrics Pulmonology, Subcommitte on Obstructive Sleep Apnea Syndrome. Clinical practice guideline: diagnosis and management of childhood obstructive sleep apnea syndrome. Paed 2002;109:704-12.

7. National Cancer Institute. Dictionary of cancer terms. (Diakses pada tanggal 20 Maret 2012). Diunduh dari http://www.cancer.gov/dictionary? ${ }^{2}$ drid $=346465$.

8. GreenFact. Neurobehavioural. (Diakses pada tanggal 20 Maret 2012). Diunduh dari http://www.greenfacts.org/ glossary/mno/neurobehavioural-neurobehavioral.htm.

9. Brockmann PE, Urschitz MS, Schlaud M, Poets CF. Primary snoring in school children: prevalence and neurocognitive impairments. Sleep Breath 2012;16:239.

10. Ali NJ, Pitson D, Stardling JR. Snoring, sleep disturbance, and behavior in 4-5 years olds. Arch Dis Child 1993;68:360-6.

11. Ali NJ, Pitson D, Stardling JR. Natural history of snoring and related behavior problems between the ages of 4 and 5 years. Arch Dis Child 1994;71:74-6.

12. O’Brien LM, Mervis CB, Holbrook CR, Bruner JL, Klaus CJ, Rutherford J, dkk. Neurobehavioral implications of habitual snoring in children. Paed 2004;114:44-9.

13. Chervin R, Dillon J, Bassetti C, Ganocczy D, Pituch K. Symptoms of sleep disorder, inattention, and hyperactivity in children. Sleep. 1997;20:1185-92.

14. Aronen ET, Liukkonen K, Simola P, Virkkula P, Uschakoff A, Korkman M, dkk. Mood is associated with 
snoring in preschool-aged children. J Dev Behav Pediatr 2009;30:107-14.

15. Urschitz MS, Eitner S, Guenther A, Eggebrecht E, Wolff J, Urschitz-Duprat PM, dkk. Habitual snoring, intermittent hypoxia, and impaired behavior in primary school children. Pediatrics 2004;114:1041-8.

16. Ferreira AM, Clemente V, Gozal D, Gomes A, Pissarra C, Cesar H, dkk. Snoring in Portuguese primary school children. Paed 2000;106;64-9.

17. Eitner S, Urschitz MS, Guenther A, Urschitz-Duprat PM, Bohnhorst B, Schlaud M, dkk. Sleep problem and daytime somnolence in a German population-based sample of snoring school-aged children. J.Sleep.Res 2007;16:96-101.

18. Urschitz MS, Guenther A, Eggebrecht E, Wolff J, Urschitz-Duprat PM, Schlaud M, at al. Snoring, intermittent hypoxia, and academic performance in primary school children. Am J Resp Crit Care med 2003;168:464-8.

19. Gozal D, Pope Jr DW. Snoring during early childhood and academic performance at ages thirteen to fourteen years. Paed 2001;107:1394-99.

20. Supriyatno B, Deviani R, Tumbelaka A, Kariani EBK, Rahajoe NN. Characteristics and risk factors of snoring and the prevalence of suspected obstructive sleep apnea in children. Pediatr Indones 2005;45:40-5.

21. Nafiu OO, Burke CC, Chimbira WT, Ackwerh R, Reynolds PI, Malviya S. Prevalence of habitual snoring in children and occurrence of peri-operative adverse events. Eur Jour of Anesth 2011;28:340-5.

22. Schechter MS. Technical report: diagnosis and management of childhood obstructive sleep apnea syndrome. Paed 2002;109:1-20.

23. Li AM, Au CT, So Hk, Lau J, Ng PC, Wing YK. Prevalence and risk factors of habitual snoring in primary school children. Chest 2010;138:519-27.

24. Carbo GM, Forastiere F, Agabiti N, Pistelli R, Dell'Orco V, Perucci CA, dkk. Snoring in 9- to 15-year-old children: risk factors and clinical relevance. Paed 2001;108:1149-54.

25. Anonim. Mendengkur atau mengorok .(Diakses pada tanggal 15 Januari 2012). Diunduh dari http://sehatenak. blogspot.com/2009/08/mendengkur-atau-mengorok.html.

26. Supriyatno B. Faktor risiko obstructive sleep apnea syndrome pada remaja dini obes: sistem skor sebagai prediksi diagnostik. Act Med Indone 2010;42:152157.

27. Brouillette RT, Hanson D, David R, Klemka L, Szatkowski A, Fernbach S, dkk. A diagnostic approach to suspected obstructive sleep apnea in children. J Pediatr 1984;105:10-4.

28. Redline S, Tishler PV, Schluchter M, Aylor J, Clark K, Graham G. Risk factors for sleep-disordered breathing in children. Association with obesity, race, and respiratory problems. Am J Respir Crit Care Med 1999;159:152732.

29. Urschitz MS, Guenther A, Eitner S, Urschitz-Duprat PM, Schlaud M, Ipsiroglu OS, dkk. Risk Factor and Natural History of Habitual Snoring. Chest 2004;126:790-800.

30. Marcus cl, carroll jl, obstructive sleep apnea syndrome. Dalam: loyughlin GN, Eiger H, penyunting. Respiratory disease in children: diagnosis and management. Baltimore: William \& Wilkins; 1994.h. 475-91.

31. Guilleminault C, Li JH. Does benign” primary snoring” ever exist in children?. Chest 2004;126:1396-8. 